\title{
An Environment without Barriers
}

\author{
Adem Spahiu \\ Teaching staff in College Heimerer (Kosovo) \\ Mimoza Zylfiu
}

\begin{abstract}
In Kosovo is not known the exact number of persons with disabilities. According to the WHO, it is estimated that up to $15 \%$ of the general population may be persons with disabilities. the fundamental right of persons with disabilities is that htye live within their community where they can circulate and participate wituhout obstacles in the wider social life, cultural, labor, etc. As in education, according to our research the assessment made by we and the UNICEF, reported that in Kosovo only $11 \%$ of children with disabilitites are involved in the education system. Based on the research and other informations from islolated disabilities persons in Kosovo, indicate that consenquently being denied from fundamental rights and free movement, may causes separation from social life, also this may casue difficulties for full socialization and integration, as a very important factor in development and preparation for every day life acitvities. Building an eniviroment without barriers is obviosly a very important issue for the inclusion of persons with disabilities in all sectors of social life,for the purposes of their integration in different areas of life: social, eductional, training and working employment. Purpose of the research is to identify and analyze the mainbarriers that impede the free movement of persons with disabilities and to create a an enviroment without barriers. Necessary data for study are collected in some places of Kosovo. For research we have used quantitative methods, selections of citizens has been in casual way without any specific criteria. Collection of data and creation of questioner is made based in necessary elements or right questions for as clear as possible identification of the problem.
\end{abstract}

Keywords: right's, disabilities, citizens' barriers, information, care

\section{Introduction}

In Kosova is not known the exact number of persons with disabilities. According to the WHO, it is estimated that up to $15 \%$ of the general population may be persons with disabilities. the fundamental right of persons with disabilities is that htye live within their community where they can circulate and participate wituhout obstacles in the wider social life, cultural, labor, etc. As in education, according to our research the assessment made by we and the UNICEF, reported that in Kosova only $11 \%$ of children with disabilitites are involved in the education system.

Based on the research and other informations from islolated disabilities persons in Kosova, indicate that consenquently being denied from fundamental rights and free movement, may causes separation from social life, also this may casue difficulties for full socialization and integration, as a very important factor in development and preparation for every day life acitvities.

Building an eniviroment without barriers is obviosly a very important issue for the inclusion of persons with disabilities in all sectors of social life,for the purposes of their integration in different areas of life: social, eductional, training and working employment.

Purpose of the research is to identify and analyze the mainbarriers that impede the free movement of persons with disabilities and to create $a$ an enviroment without barriers.

Necessary data for study are collected in some places of Kosova. For research we have used quantitative methods, selections of citizens has been in casual way without any specific criteria

Collection of data and creation of questioner is made based in necessary elements or right questions for as clear as possible identification of the problem. 


\section{The purpose of the research}

Research "An enviroment without barriers"- aims t idnetiy and analizy the main barriers that impede the free movement of persons with disasbilities, as well as praktice and training them for life and work.

Indetification of these barriers with doodwill of the society will enable obercoming them, in order to create a better enivonment for a functional envioroment for development and finding of these persons.

This research aims to identify specific steps that can be taken to start solve the problems.

A key objective of the research is to develop an overview and guidenc that can be used by government, advocasy group, donos and non-governemntal organization to improve for people with disabilities and services based on the needs and theris rights.

\section{Methodology}

Regading the problems of persons with disabilities and for lighting of the different situations and siocial and individual attiutdes to solve them, will be applied the methodology research in the samples of the population involved in the research of the highly complex and sensitive problem.

In esploratary reseach will be included:

Family members of persons with dissabilities

Persons with Disabilities

Educatioon institutions ( schools, primary and basic secondary education and preschool)

Centres of social work

Association for persons with disabilitites

State-government institutions dealing with care for persons with disabilities

Municipal or regional insitutions for employment, etc.

Selected sample ( representative sample)- should be providet on the appropriate criteria for the validity of the final results, the results of witch will enable: lighting the problems of people with limited ability, drawing the conclusions and appropriate recommendations, etc.

Among the methods to be applied during the research of this issue will be:

- Observative- descriptive method of forms, contents and acitivities in the areas and research areas related to persons with limited ability.

— Method analysis of printed documentation and written about the laid-mentioned problem.

Thechniques-the mos important instruments that will be applied during the research process research of the laid problem will be:

\section{Survey( questionaire)}

Interviews and

Collection of documents ( material) printed and written analysis.

After accumulation of the research material by statistical techniques and analysis of the material the final results will be issued at the proper interpretation. By issuing the appropriate conclusions and recommendations, the material wich will be distributed relevant institutions for the issues of the personal problems with limited ability. 


\section{Interviews}

One of the questionnaries that are used is this:

Questionnaires to residents

Gender?

Residents?

Educaton rate?

Postiton socio-economice?

At what age did you start to come to this institute?

What you will change in this institute?

Livelihoods in this institution?

Daily activies?

How are physical conditions?

The way the family visits?

Somethings to add by the resident?

Figure 1. Number of persons with dissabilities and cmobined in the Kosova Municipality 1

\section{The number of members in the Municipality}
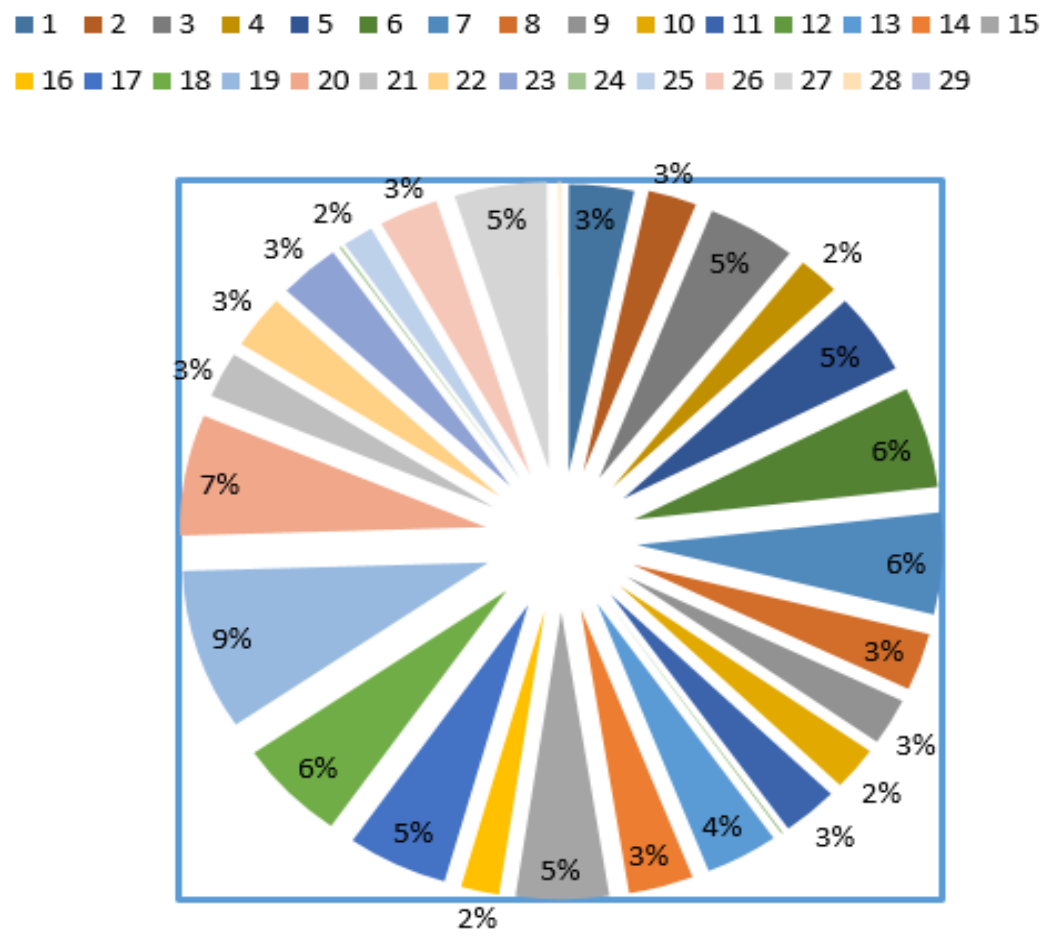

Figure.2 The causes of disability by gender and ethnic group ${ }^{2}$ 


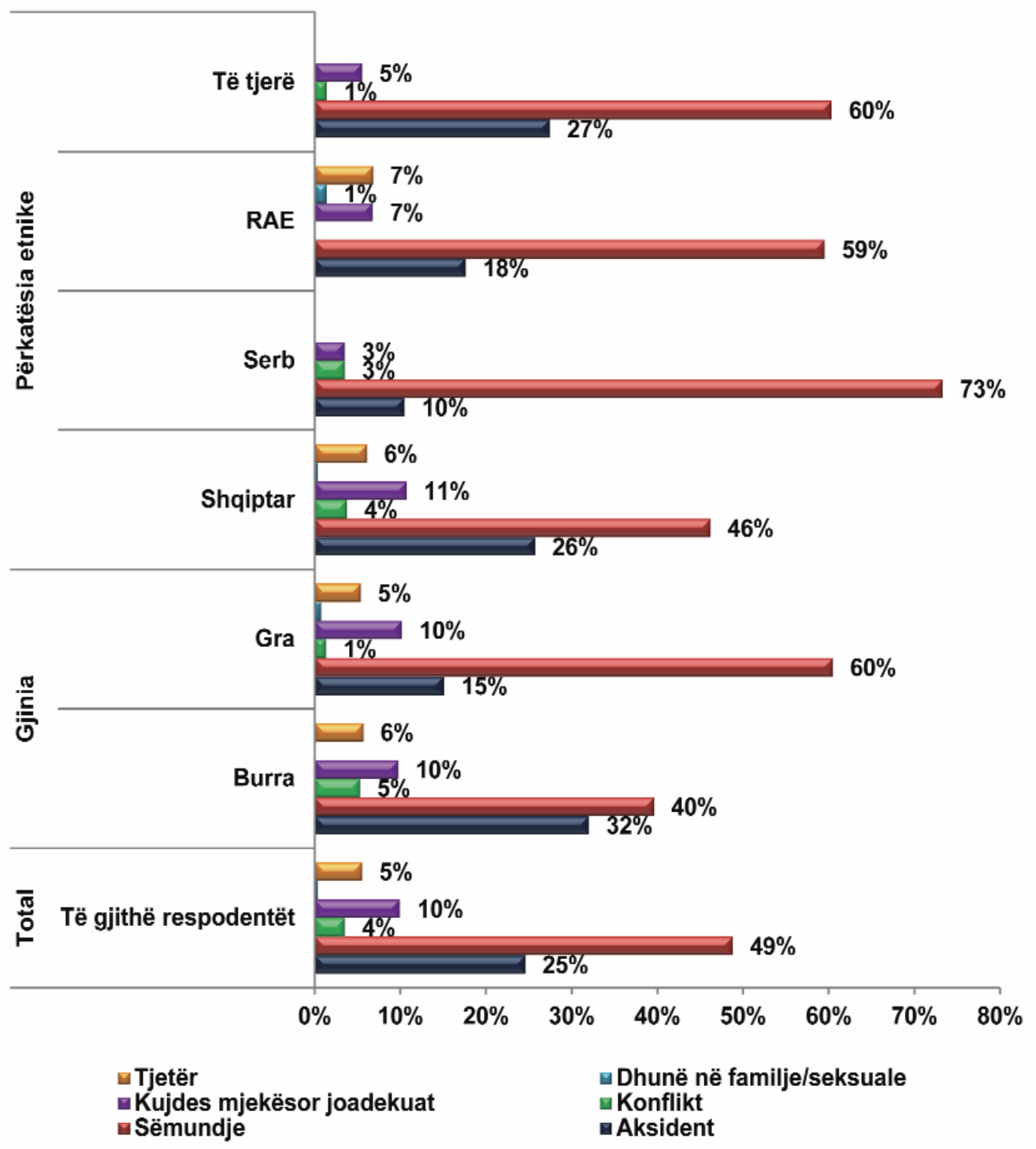

Considering the differences between the spectrums of ethnic groups, the Serbs have the gighest percentage ( 73 percent) of impairment resulting from the disease followed by others with 50 percent. Respondents Albanians and other precent similar percentage- 26 percent and 27 percent - of disability caused by accident. Concern percentage, even is low (1.4 percent) was observed in the group of Roma, Ashkali and Egyptian, who indicate domestic violence9 secual as the originationg source of their limited ability (see Figurie 2)

Access of the society towards disability

One of the most concrete guidance and practical to disability in Kosovi is : comprehensive policy framework on disability issues in Kosova", which was launched in 2001. This guide proviedes recommentations to regulate matters relating to persons with disabilities as follows. 


\section{Social Model and Human Rights}

Social Model and Human Rights, considers disabiluity as a social problem that requires response from society. Persons with disabilities are jointly mobilized and own organized. Their goal is to buid a civil movement which is controlled by persons with disabilites. In the movemend of persons with disabilities central thing is the apperance of disability as an issue of human rights and developemnt in general. This leads to the recogintion and acceptance of disability as a normal part of life, that people with disabilities are equa; citizens and therefore should enjoy equal rights but also responsiblities

\section{Key findings in the research}

Some of the main barrier faced by persons with disabilities in Kosova in order to acces the most comprehensive social life are:

The economic situation-in post-war Kosova's economic situation was dificult. With the advent of international were opened new jobs and national organisations, as well as public institutions. This led to some emprovement in the economis situation of the population in general in Kosova, however, regarding persons with disabilities, for them the barriers continued because they coud not work in these organizations and insitutions for various reasons, such as innapropriate infrastrucutre iliteracy, low level of awareness of empyers, etc.

Acoording information from NGOs of persons with dissabilies, it appears that they do not have any statistics on the number of persons with dissabilities in Kosova who are employed to word in any form, even self-emplyemnt. We know that this number is very small and only associacons of persons with dissabilities employ these people. In state institutions and public administration as well this number is very small. According to low No. 03/L-019 for vocational rehabilitation and employment of persons with dissabilities, the Ministry of Labour and Social Wealfare to establishe the maintain statistics on the number of jobs seekers and emplyees are persons with dissabilities.

Vice President of the the Associacion of the Blind and Visually impaired said that the ecast number of people blind and visually impaired is not known. Employment is terrible; very few are eplmoyed, because of the that they facing other problems as economis and social issues. Are very poore, because they are not employed reciving a pension of 60 euros which is not enough for anything. According to him, Kosova is estimated to have about 2.000 blind, from these number is estimated to be emplyed only $2 \%$. They are also employed in the public sector and the privat sector. Social assitanc which blind persons recived hase made them to stay inside their home and not seeking work.

While a survey conducted by UNDP, who acted in a part of Kosova, signed between socio-economic status of the families of persons with dissabiliites, by sex, ethnic group and tybe of residence as these data come follows.

Figure 3.Socio-economic status of the family of the disabled persons, according to their gender, ethnicity and type of residence 


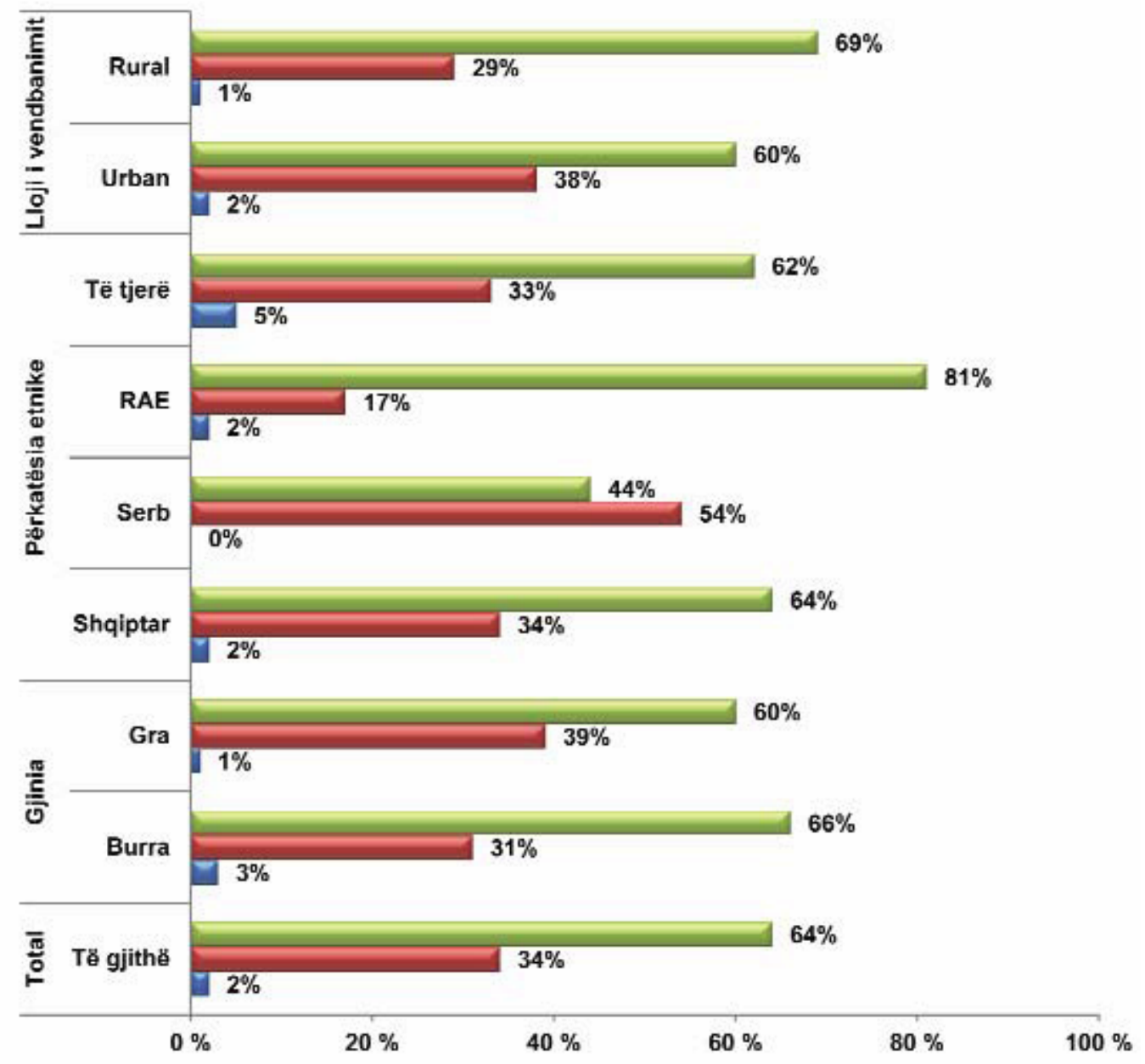

\section{$\square$ Nën mesatar}

- Mesatar

घhi mesatar

Results by gender, ethnic group and type of settlement, women, Serbs and those living in urban areas describe their economic well-being as the highest percentage in comparison with men, Albanians, Roma, Ashkali and Egyptians and those living in rural ( see figure 3$)^{1}$

Disabled war- divided into several categories and varies category depending on the rate of payment.

As benificiaries of the social scheme of war invalids are 3487 earnings divided by the degree of disability that begins with $20 \%$ disability. Social schemes are shared with the deegre of disability payment starts from 130 euro who are cilivian war invalidsl. But participanting categories of the KLA start from $20 \%$ to 180 euros up to $81 \%$ and further that is still with the assitant.

Figura 6 Number of disabled war in Kosova Municipalities

\footnotetext{
${ }^{1}$ Broad survey of persons with disabilities in Kosova p.17
} 


\begin{tabular}{|c|c|c|c|}
\hline \multicolumn{4}{|c|}{ Invalidëve të UÇK-së } \\
\hline Nr. & male & female & municipality \\
\hline 1. & 244 & 4 & Deçan \\
\hline 2. & 10 & & Dragash \\
\hline 3. & 111 & 1 & Ferizaj \\
\hline 4. & 34 & 1 & F. Kosovë \\
\hline 5. & 185 & 2 & Gjakovë \\
\hline 6. & 47 & 2 & Gjilan \\
\hline 7. & 411 & 7 & Gllogovc \\
\hline 8. & 43 & 3 & Istog \\
\hline 9. & 72 & 1 & Malishevë \\
\hline 10. & 14 & & Kamenicë \\
\hline 11. & 121 & 3 & Klinë \\
\hline 12. & 66 & & Lipjan \\
\hline 13. & 130 & 1 & Malishevë \\
\hline 14. & 138 & 1 & Mitrovicë \\
\hline 15. & 2 & & Novobërd \\
\hline 16. & 34 & & Obiliq \\
\hline 17. & 179 & 3 & Pejë \\
\hline 18. & 220 & 1 & Podujevë \\
\hline 19. & 417 & 14 & Prishtinë \\
\hline 20. & 135 & 4 & Prizren \\
\hline 21. & 97 & & Rahovec \\
\hline 22. & 5 & & Shtërpce \\
\hline 23. & 87 & 1 & Shtime \\
\hline 24. & 294 & 2 & Skenderaj \\
\hline 25. & 192 & 1 & Suharekë \\
\hline 26. & 14 & & Viti \\
\hline 27. & 131 & 1 & Vushtrri \\
\hline 28. & 1 & & Zveçan \\
\hline
\end{tabular}

In Kosova municipalities, social assistance beneficiaries of war invalids are in total: 3487 , where 3444 men and 43 women. Guardian for disabled persons with bodily injury with over $80 \%$. In addition to war invalids are included families of invalids after death (including spouse and children under the age of 18 years respectively 26 years

if they are in education), civil disabled, civilian invalids families after death, families of martyrs, families of missing KLA, families of the civilian victim, families of civilian disappeared, war invalids caregivers and civilian invalids caregivers.

The average salary for war invalids is $192.9 €$

Low economic development did not contribute to the lives of people with disabilities in improving the welfare and development of their social life, while UN data reports that poor nutrition, life-threatening work (including accidents (Fletcher and Hurst, 1995) clearly indicate the current position of persons with a high risk of physical disability, lack of knowledge on the health and care of maternity, personal and public hygiene, poor sewage and natural disasters, disability in Kosova.

- Living costs of persons with disabilities and institutional care - Persons with disabilities have specific and costly needs that for the Kosova standard are still far from the minimum reach of their achievement.

People with disabilities are known to enjoy a pension that does not meet their needs in the near future. When we associate this with the need for associates of the largest number of people with disabilities, a companion who has a cost, then we can say that their material position is far from the needs. 
Today, no support equipment is provided by the country's institutions and the basic needs of people with disabilities. Providing this need is made by non-governmental organizations that have no sustainability and are based solely on projects and donations of goodwill.

While in the areas where wheelchairs are free, crutches, hearing aids, and maintenance are expensive, and this situation makes it more difficult for these people with disabilities to develop.

\section{Example}

"Sometimes auxiliary equipment (carts) due to inadequate infrastructure lead to breakdowns and defects, which can be adjusted with a small repair, but usually these cost and the NGOs that provide these services have no durability material. "(A middle-aged man, capital of the capital, employed us.)

Figure 11. Percentage of unemployment, by type of disability. ${ }^{1}$

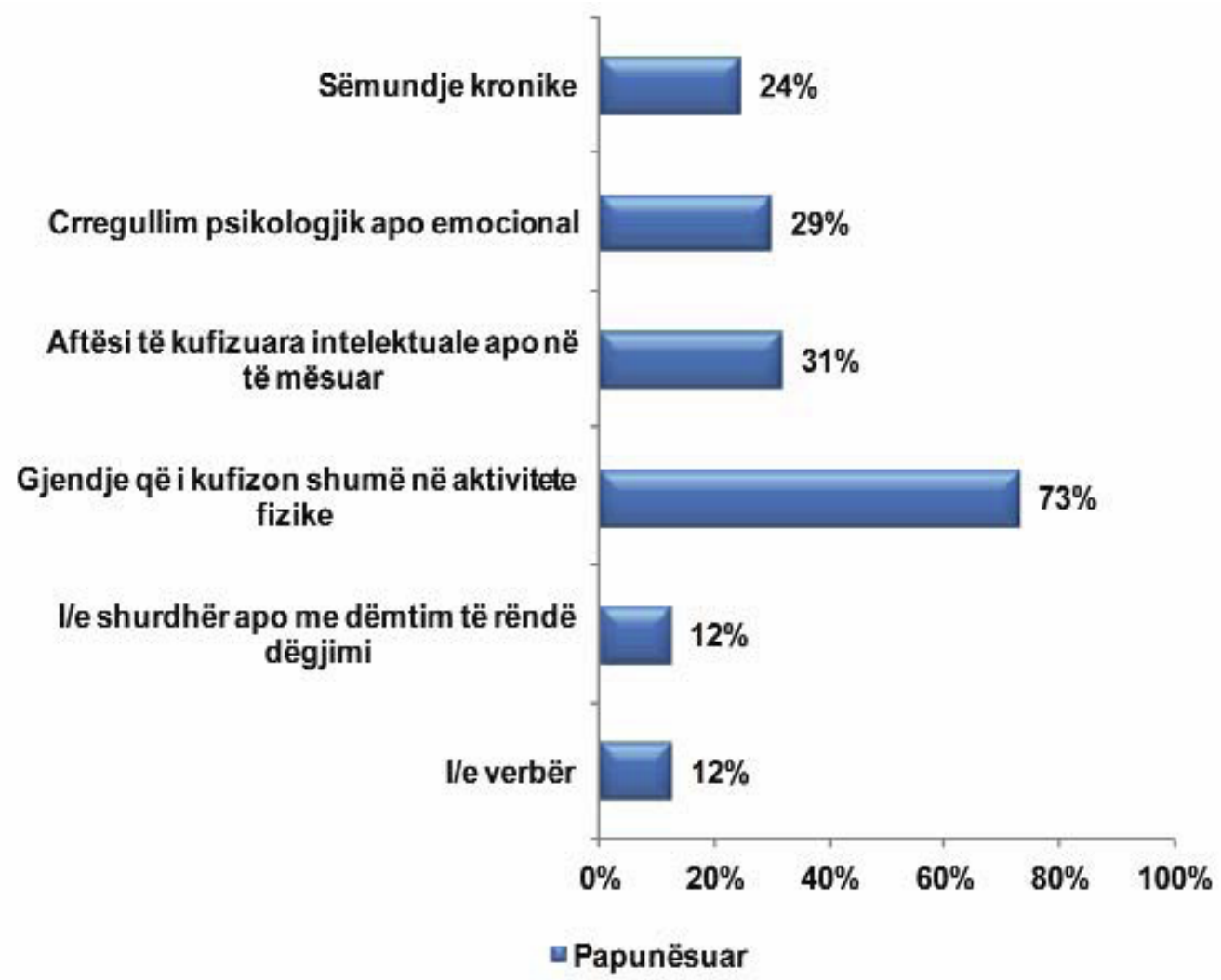

The highest percentage of the unemployed is among those in whom the situation substantially limits physical activities. However, the percentage of unemployed respondents with other types of disability is also high (see Figure 11)

- Female and Disability- The position of women in our society still being charged with a traditionalism and conservative elements in general is still in a non-enviable position compared to male gender, a phenomenon also reflected in the approach of persons with disability with gender. This low status makes them more prone to poverty and marginalization.

To illustrate this we have the following examples, those that live in large families as a young man declares: "I live in a large family, I have four brothers married, all have their families. Parents have died, as parents do not support, and my kings do

${ }^{1}$ Comprehensive Survey for Persons with Disabilities in Kosova p.43 
not help. I often heard them saying, "With the hell and the quakkah, where I look after them all" and to bring me the "crippled" (Shows a woman with physical disabilities, paraplegia.)

While the second example specifically shows marriage against her will, which states: "My family is poor and many members, when I grew up for 19 years, my family began to interest me as a memoir, pam pyt mu. They found me an elder and a martyr for helping my family first and for memes of my life and my sake. (Shows a woman of the age of 29, with physical disabilities.)

"This is why you come out on the road when you can not walk."

At a wedding, a woman has told me "what kie a sakat je".

Figure 7. Percentage of women and men with disabilities and combined in Kosova 1

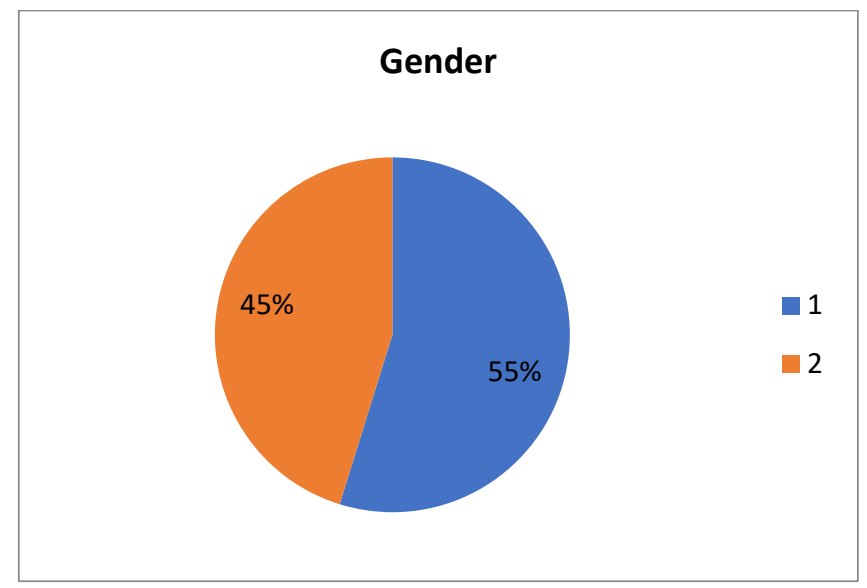

The table shows that the largest number of physical and combined disabilities are men with $55 \%$ and women with $45 \%$ (see Figure 7)

Infrastructure- The way in which the physical environment is developed and organized greatly impedes the level of independent and equal living of persons with disabilities and other citizens. The current situation shows that in our organization the infrastructure mainly does not meet the needs of people with disabilities. One of the main barriers for people with disabilities is the physical barriers that hinder people with disabilities to realize their rights in education, employment, training, recreation, health care, participation in political life, etc.

In general, access to health facilities is difficult for all types of disability. At University Clinic Center of Kosova (UCCK), hospitals at their entrance have adjusted the wheelchair access, while the elevator (vertical access) is, in most cases, unusable, as most elevators are not maintained and are out of service. Rooms at UCCK are overloaded with beds and it is impossible to move the person with a wheelchair in them. Existing toilets in hospitals and family medicine centers are very small and are not suitable for use by wheelchair users

- Communicating - Knowing how difficult it is to include people with disabilities in communication (deaf persons) on the inability to use sign language and the lack of materials and documents in the Braille alphabet (blind persons) by institutions ours, it makes their integration more difficult.

Based on the analysis of the situation of persons with disabilities in Kosova, made by Handicap International, the HandiKos approach (physical infrastructure) in public places is estimated at $65 \%$ as a very problematic issue.

People with disabilities in Kosova, which according to international estimates can be 150,000 , live in conditions of poverty, isolation and inferiority. Their experience has been exacerbated by the conflict and population movements that have prevailed in Kosova over the last few years. It is an important remark that disability not only affects the individual but also

\footnotetext{
${ }^{1}$ NGO HandiKos database
} 
his family and the community where he lives and operates. The number of those affected by disability is quite large, including the large number of families living with them, in particular by implying traditional families in our country where often the number of members of a family is large enough .

- Inclusion of people with disabilities in society

a) The state of the current infrastructure in Kosova for equal access to free and unhindered access for people with disabilities rarely presents difficulties in their participation in everyday life, education, employment and vocational training;

b) Persons with disabilities who are not in equal position due to their psychological and physical condition or health status can not be a participant in the process of lawmaking and the creation of the right and proper attitude of the society to creating their own and appropriate conditions and needs;

c) Transmission and free circulation - During the research, interviewers indicated that they need travel assistance if they are not accompanied by escorts, since mainly urban and interurban transport vehicles do not have the appropriate technical equipment to facilitate travel (due to lack of escalators, lack of bragging alphabet, etc.). It should rely on assistance from the transport worker or other passengers. They often encounter problems when they miss occasional help or when they seek help. It happens that wrongly granted assistance can harm a person with disabilities in self-esteem.

illustration: "Many times when I ask for help from passers-by to cross the road, they unintentionally do this by tightening my shirt collar. At that moment I feel so inferior and insignificant." (Describes the situation of a person with visual impairment.)

A person with a disability at first described an incident where he had asked a traveler to tell him when their bus had arrived. The traveler had left without announcing it and as a result, the disabled person was left standing waiting for an indefinite transportation, explains the person with disabilities at sight.

From the above illustrations it can be concluded that despite the efforts of the citizens who have higher awareness towards the people in need, their problem can and should be solved only by the institutions and their solution must be sustainable.

Identified group participants, high transport prices, lack of proper awareness amongst transport personnel towards persons with disabilities and the general public and the needs of disabled passengers, barriers in the transport system as main obstacles that they face, show that the problems identified have an enormous impact on the violation of their fundamental rights for free movement as citizens of Kosova.

Also, as a problem for public transport utilization, people with hearing impairment and / or speech impairments often encounter communication difficulties with workers and other travelers. Lack of visual information on transport vehicles presents difficulties in selecting the destination requested by persons with disabilities. Usually the sign language is not understood and the ability to write ticket requests or information is not always a solution to the problems of people with disabilities, because a number of them do not know the literacy.

Because of the inadequate transport for persons with physical disabilities (wheelchair users) the only solution to some extent in the city of Pristina, they may be only taxis for their journey, but this also exacerbates the cost of living them.

- Lack of slopes in some locales and sidewalks without the appropriate walkway for people with disabilities prevents them from doing loose movement. Ponds, unmarked pit roads, the small number of traffic lights with acoustic signals for people with disabilities and their failure to function properly, road dumps and difficult crossings create obstacles to the development of the movement and can also affect the deterioration of disability or any other obstacle. All of this implies that they have difficulties in meeting their needs in social life.lllustration: "When I went to the Center for Social Work, I encountered various physical barriers, starting from inappropriate sidewalks, especially at the entrance of the main CSW, whereby a citizen tried to help me enter the CSW, but unfortunately I got angry and the citizen felt too bad. (Explains a male person, a wheelchair user).

Health services-The medical service and the level of treatment should be appropriate and acceptable to all, which is the basis for equalizing opportunities for people with disabilities. A disabled person can not perform medical services without the assistance of an assistant at all hospital centers due to stairs, lifts that in many cases do not work, lack of sign language knowledge starting with the worker who works at the door and in the absence of the writings of the Brain, as well as the inscriptions which give priority to persons with disabilities. 
From research conducted in the Deaf Association of Kosova, access to health services in Kosova is poor (85\% out of 100 respondents say access to health services is poor, $1 \%$ say access to health services is above average, $11 \%$ say the approach is poor toward the average).

As for the question asked by the NGO representative HandiKos: How is physical and personnel access, as well as other patients, compared to the person with disabilities in healthcare institutions? It shows that: The physical access of persons with disabilities to healthcare institutions is miserable, especially for wheelchair users. According to some of our researches and other associations of people with disabilities, access to health facilities in state institutions is as follows: $90 \%$ of facilities have access to wheelchair users only on the ground floor, $10 \%$ have access to the high floors as well which have lift and are in usable condition. Another physical disadvantage in these facilities is the inability of wheelchair users to use in the toilets. Few objects have proper access to the toilets - he adds.

Regarding the access of health personnel, they often have no knowledge of the type and origin of disability, so this affects more and more the deterioration of their situation and in most cases persons with disabilities are expected to (just as sick), and do not take into account the daily and current health problems that come due to disability. Illustration

When I get to the doctor with the Vlach an injection, I have a few more pots and injections and I do not have feelings in the body parts.

Figure 8. PWDs who need therapy by age

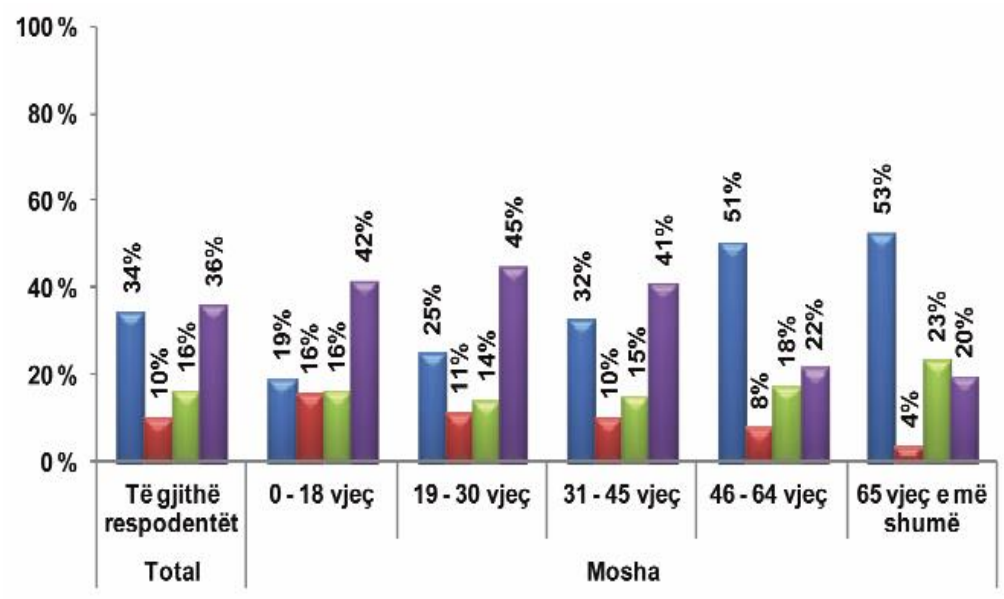

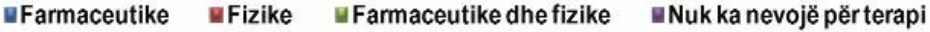

Respondents in need of treatment suggest that roughly 34 percent of people with disabilities need pharmaceutical treatment and 10 percent physical improvement, while 16 percent of respondents need both. 78 percent of PWDs who need pharmaceutical treatment are taking, but more than half (54 percent) of those in need of physical treatment are not being treated, most often because it is too expensive ( 65 percent). Among those who need both treatments, 52 percent are accepting, while 23 percent are not. It is also worrying that 9 per cent of PAKs who need physical treatment are only receiving treatmentfarmaceutik, gjëqë lë të kuptohet se ata marrin hapa për dhimbje, apo qetësues, në vend të trajtimit për të cilin ata me të vërtetë kanë nevojë ( Shih figurën 8) ${ }^{1}$

Education - The issue of education of people with disabilities is quite complex and requires a special professional approach. Our educational system and school education, although having an educational and pedagogical work with

\footnotetext{
${ }^{1}$ Comprehensive Survey of People with Disabilities in Kosova, p.33
} 
children with developmental obstacles, conclude that organizing educational and educational activities with these children should have a different approach that includes a range of requirements.

In addition to creating the right infrastructure for these children (for which it has been mentioned before) the professional didactico-methodical preparation of the teaching staff is not yet sufficiently level to meet all the requirements of the working program with these kids.

Today, when talking about children with disabilities, we think of children who are under stress, and this requires that in the process of their education a focused commitment to the disordered function is practiced, but keeping in mind the complete state of personality of them.

In such cases these children with disabilities should be treated in line with the developmental scale and work according to the developmental performance of the social environment of the class they are in. For this, the forms of contemporary organization are more than necessary in the developmental process of teaching work. For which, according to the degree of developmental deprivation of the child, it is necessary to determine the form and contents of didactic-methodological actions. In this regard, if we are dealing with the developmental slowdown that relates to the joint work of these children in the regular social environment of the classroom, regular teaching staff should have a culture of preparing for work with these children it is preferred that they also have profiles assistants from special pedagogy. Whereas the organization of special classes that can operate at ordinary schools, for the most severe retardation, children are sent to special schools, in which the external and internal organization of the teaching work is developed on the basis of the developmental scale of these children.

According to UNICEF's assessment, it is reported that in Kosova only $10 \%$ of children with disabilities are involved in the education system. This is due to the difficult economic conditions of families, the inadequate physical infrastructure, inadequate assessment by the assessment committees, the prejudices that exist on the part of the institutions and the low awareness of the child's family. This situation shows and leads to the inability of their best preparation, so that in the future they will be able to find a job and not be more deferred to poverty.

Figure 9. Percentage of respondents who have / did not attend school, by type of Disability

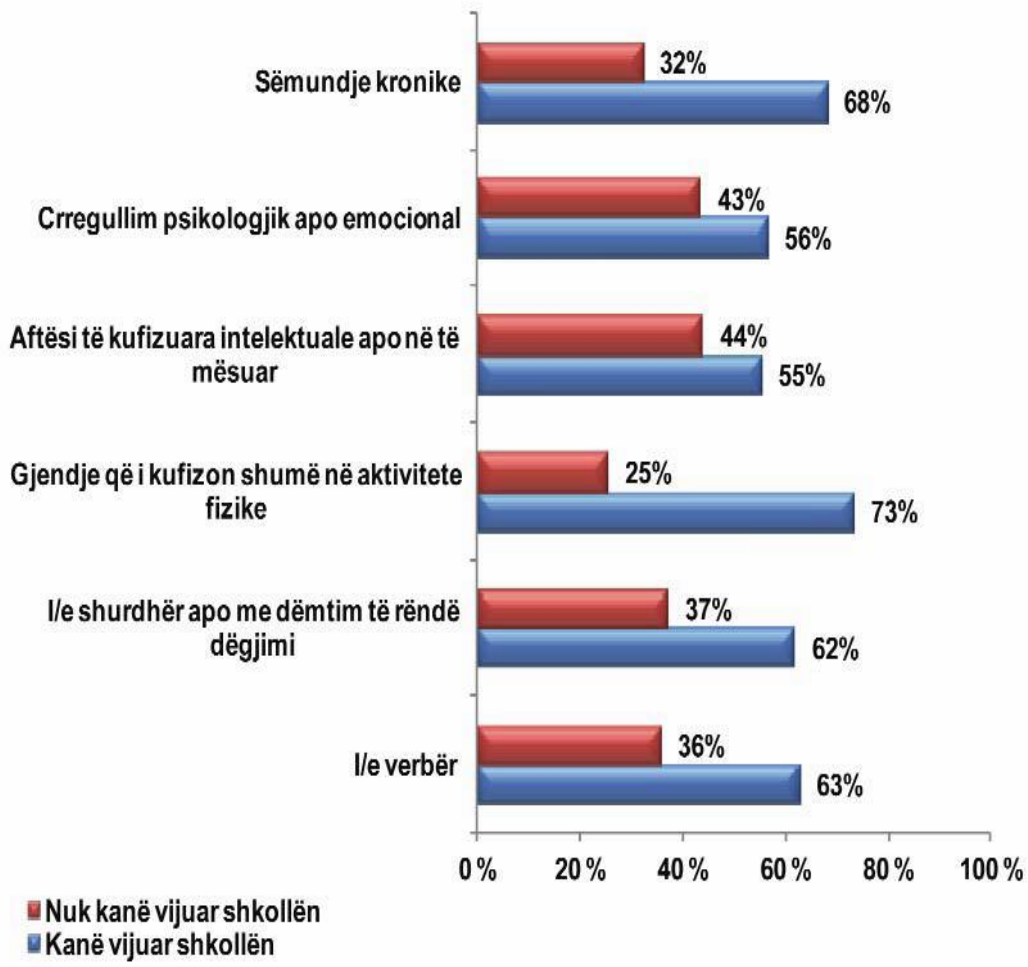


Respondents with physical disabilities attended school more often ( 73 percent), then those with intellectual problems (55 percent) and those with psychological disorders (56 percent). Persons with chronic illness also more often claim (68 percent) that they did not attend school compared to respondents with other handicapped persons. Respondents to whom disability is diagnosed more late life have attended school more often (76 percent) than those to whom the impaired ability was diagnosed early (65 percent) (see Figure 9)

Figure 10. Percentage of persons with physical and combined disabilities who have and did not attend school

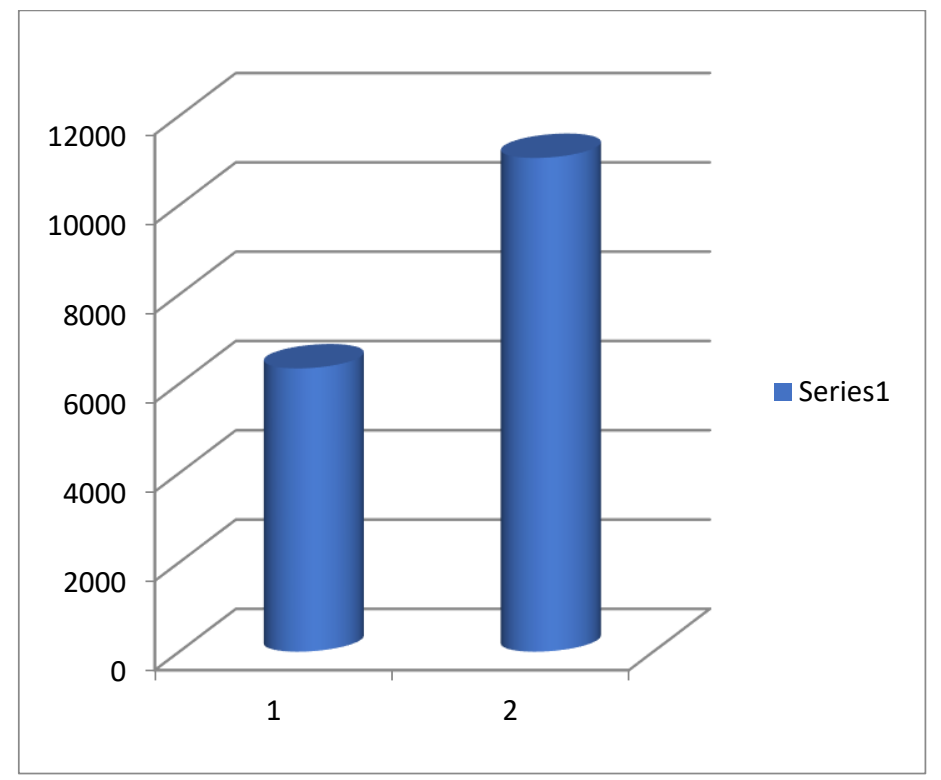

Respondents with physical and combined disabilities attending school are 6345 , while respondents who did not attend school are 11058 (see Figure 10)

-The role of CSO-S and NGOs to improve the situation of persons with disabilities.

\section{a) The role of non-governmental organizations}

The organization of the social and professional activity of people with disabilities in Kosova, as we have noted above, has a long developmental experience and now we can say that the main bearer of activities in terms of non-governmental development activity should be distinguished by HandiKos -i. Which is the main provider of support and rehabilitation services for people with physical disabilities and has established a network of Community Centers and Active Local Groups of People with Disabilities.

In addition, NGOs now operate in Kosova with a considerable number of associations which, with their activities, are profiled according to the character of persons with disabilities such as the Association of the Blind, the Association of the Deaf, the Association of Speech Therapists, the Association of the Autistic, Red Cross,

Association of Doom Syndrome Kosova, SOS-Kinderdorf, Kosova. Which, as social and professional associations, operate with their programs in the development interests of their members and are an integral part of society.

\section{Some data from NGOs}

- In the Syndrome Down Syndrome of Kosova, there are 670 people affected by down syndrome, while the number of deaths in the last three years is up to 18 people. Regarding education, 57 children are enrolled in regular education and over 112 in special education and attached classes; 
- In SOS Kinderdorf, there are three children with light physical disabilities aged 2-4, as well as a child with mental retardation of 3 years of age. There are 7 children with physical and mental disabilities in the garden who are from 3-6 years of age.

- Deaf Association of Kosova, estimated to be around 7,000 to 8,000 deaf persons. According to FAD (2004), it is thought that there may be 3 deaf people in 1000 people in Kosova. WHO estimates that $0.2 \%$ of the entire population is classified with deep lost hearing (81 dB or more). If we take these WHO estimates, it turns out that the total number of deaf people in Kosova is 3,600. So, the approximate estimate of the deaf population in Kosova is between 3,600 (WHO) - 7/8000 (AAC).

A number of international NGOs have supported local organizations of people with disabilities in Kosova, which some NGOs are still supporting

\section{b) Non Govermental Organization}

From government organizations that support and lobby for people with disabilities are: MEST Office, MoH, DMS.

Near the Ministry of Labor and Social Welfare are:

Institutional Care Division (DPI), which operates within

Department of Social Welfare with the following three sectors:

- The Department for Mental Disabilities,

- Sector for Elderly and Non-Family Care Sector,

- Complaints Sector.

Under the managing of the Ministry of Labor and Social Welfare are two very important institutions where there are also persons with disabilities:

-Special Institute of Shtime- After the end of World War II in the former school for households in Shtime was established the House - a shelter for elderly who did not have family care. The period after the 90s is the period of separation of this institution from the House of the elders (on 22.06.1991) and its functioning as a separate institution.

Some of the residents are from 1969. The youngest are 19-24 years old.

Figure 12. Residents with disabilities in Shtimè Institute

\begin{tabular}{|l|l|}
\hline \multicolumn{2}{|c|}{ Nr. The total rezidents in Shtime Institute is 59} \\
\hline Male: 38 & Female: 21 \\
\hline
\end{tabular}

There are 59 residents in the Shtime Institute: 38 men and 21 women. From Kosova, Serbia Bosna maska, Hungary and from Gora (see Figure 12)

- House of elderly people and family care-In the early 1947s, the elders' home was in Shtime, in the late 1960s, moved to Pristina, where the Raider Foundation helped. Then there was built in the yard of an elders house an object where refugees were settled from Albania. The elders' home was under the supervision of the Secretariat for Health, while the Institute for Social Policy, namely at that time the Provincial Entity for Social Policy and Professional Orientation, conducted professional supervision.

The capacity is for 70-80 people, which is full capacity. In this institution are located elderly persons without family care.

Figure 13. Number of residents in the home of elderly peop

\begin{tabular}{|l|l|l|l|l|}
\hline Month & Albanian & Serbian & Others & Total \\
\hline Aprill & 75 & 10 & 10 & 95 \\
\hline May & 73 & 10 & 10 & 93 \\
\hline June & 75 & 10 & 10 & 95 \\
\hline
\end{tabular}


In the column "Others", are included the number of persons placed in the home of elderly persons and without family carebelonging to these ethnic nationalities: Turkish, Bosniak, Egyptian, Ashkali, Roma, Croat, etc. ( see the table 13) ${ }^{1}$

\section{Practices of other countries}

It is estimated that more than one billion people live with some form of disability, accounting for $15 \%$ of the world's population (based on 2010 global population estimates). This is higher than the previous World Health Organization estimates, some 785 million (15.6\%) people aged 15 to older live with disabilities, while Global Burden of Disease estimates a figure of around 975 million (19.4\%) of persons. The World Health Survey estimates that 110 million people (2.2\%) have significant functional difficulties, and according to the Global Burden of Disease there are 190 million (3.8\%) who have "severe disabilities" - equivalent to disability that is considered as in quadriplegia, severe depression or blindness. Only Global Burden of Disease measures children's abilities (0-14 years), estimated to be 95 million (5.1\%) children, of whom 13 million $(0.7 \%)$ have "severe disabilities".

In other developed countries, all the needs of people with disabilities are guaranteed and covered by laws based on the United Nations Convention on the Rights of Persons with Disabilities and the Disabled People in those countries. These people are not counted as the poorest, but are contributing to the state by offering themselves to the labor market and raising their well-being.

The United Nations supports the drafting of the Standard Rules for Equalization of Opportunities for Persons with Disabilities, provides governments with a guide on the actions they will receive. The Standard Rules are adopted by the UN General Assembly on December 20, 1993. (footnotes)

According to the World Health Organization (WHO), it is estimated that around 59 million people in the world $(0.9 \%$ of the total population) with hearing loss classified as heavy losses (hearing loss of $61 \mathrm{~dB}$ or more ), (WHO 2005, Haualanddhe Colin 2009). This means 16,200 deaf and semi - deaf persons who live in

-Albania - has a National Disability Strategy that presents a plan to change their situation. As for illustration, we are presenting some of the relevant contents of this National Strategy of Albania for people with disabilities.

According to international standards, the focus of the definition of disability is shifted from the point of damage to the prospect of the development of the injured persons and their daily participation in social life, as well as the concrete measures to be taken to avoid, minimize and offset these limitations. At the same time, the focus on the policies that will be followed will vary from disability to the ability and competencies of the injured persons.

Disability policies will no longer be understood as policies for minorities, but their objectives based on the principles of equality, non-discrimination, inclusiveness and self-determination will be considered an important part of a civil rights approach to politics, being convinced that these policies have a positive effect not only for persons with disabilities, but also for other groups of society, such as the elderly. This policy is a challenge for the entire society because it should be considered as a task of society to build structures that ensure the full inclusion of people with disabilities in all areas of everyday life.

3. Associations of persons with disabilities in Albania are highly advanced in their structural development and should be considered as an important competence factor. Moreover, they already play a precious role in some activities in order to increase the participation of people with disabilities in society. Therefore their contribution should be institutionalized in the monitoring and reporting structures of the strategy.

4. It is clear that civil rights policy does not only affect the political, social and economic sphere, but also significantly affects policies in general. Therefore, the strategy will reflect this in detail and will create a comprehensive approach to people with disabilities, aiming at a system for the continued inclusion of disability in Albanian legislation. ${ }^{2}$

-Croatia - live 429,421 disabled people (9,7\%)

Croatia has a new working regulation which guarantees the right to exemption from paying the annual fee for the use of public transport by the order which was approved on the basis of the designated authority. On 6 December 2011 came

\footnotetext{
${ }^{1}$ Statistical Office

2 The National Strategy for Disabled Persons
} 
into force the new rules of procedure and the manner of exercising the right to exemption from payment of the annual fee for the use of public transport regulated by the ordinance. This ordinance was adopted on the basis of the roadside authority, which provides for a circle of people with disabilities who are entitled to relief from the payment of annual fees and tariffs, and the power to make decisions on the basis of which can achieve such rights. ${ }^{1}$

\section{Conclusion}

The number of people with disabilities is high in Kosova, based on international estimates that can range from 150,000 to 180,000 in our country (the World Health Organization report).

Based on the research conducted one of the most worrying issues is the low level of education of persons with disabilities.

In our educational and education system, greater and more serious engagements should be made in the training of current teaching staff to work with children with disabilities, as well as adequate preparation of teaching staff during their regular education as well as at levels higher degree of master's degree and specialization for different profiles.

One of the poorest groups in society in Kosova consists of people with disabilities and their families.

Despite the existing legislation, there is still a lack of adequate readiness in infrastructure and transport.

There is no support with the auxiliary tools for people with disabilities for free movement.

Employment of people with disabilities is low.

Disability is often crucial for not accepting these persons in workplaces in accordance with their professional preparation.

Persons with disabilities who are in employment relationship are faced with physical infrastructure problems for carrying out daily activities for the performance of their duties.

The degree of social and individual awareness is still at an inadequate level of understanding of the needs and the creation of conditions for a better life of people with disabilities.

There are negative attitudes of society to disability.

Physical infrastructure and transportation are very inappropriate

A comprehensive strategy on disability in Kosova is lacking

\section{Recommendations}

1. Raise awareness of society in general for people with disabilities in particular through some forms, such as:

- Greater involvement in disability in the media;

- Staff training programs of various institutions, in particular health personnel, for the most appropriate access to people with disabilities;

- Increase the number of children with disabilities involved in special education of certain categories with a tendency to include them in the regular education process.

2. For children with disabilities to have equal rights as other children in education, basic conditions must be created such as:

- $\quad$ Physical infrastructure of schools;

- Teachers' ability to work with children with disabilities.

3. For the establishment of legal infrastructure (sub-legal acts and administrative instructions) in the implementation of current laws, it should:

From the municipal level - the urbanization directorate, the implementation of the Construction Law and the Administrative Instruction on the Technical Conditions of Public Premises for Persons with Disabilities.

\section{Free Movement}

\footnotetext{
${ }^{1}$ Internet, Official Gazete nr. 136/11
} 
- Urban and inter-urban transport services should be regulated by law to supplement the right to freedom of movement;

- Access to information, communication and transport should be accessible to persons with disabilities by having access to all services in the Brajl, signs or languages that are accessible to them in the stop of the means of transport.

5. Social Assistance.

When talking about the social scheme, it should be noted that:

- The government should consider finding ways to supplement their family budget or allow all medical services for these persons to be free of charge;

- MLSW, specifically in the employment sector, should ensure that people with disabilities have access to and support in starting their own minibuses through individual, cooperative or NGO initiatives;

- MLSW should make the amount of social assistance, disability pensions and other forms of material support compliant with disability, which implies compliance to meet their health needs

6. For MLSW and private businesses

- Encourage increasing employment opportunities by recognizing the different needs of people with disabilities;

- $\quad$ Ensure communication services, access and infrastructure with appropriate employment opportunities;

- To organize various forms of training to enable people with disabilities to work.

7. The implementation of sign language and written documents in the Braille alphabet in institutional and public facilities helps disabled people to have easier access to their social life.

8. Steeple is very important for all people with disabilities to include activities and budget lines of access (construction or removal of architectural barriers in institutions that do not have suitable slopes for people with disabilities).

9. To sanction institutions that do not have suitable slopes for people with disabilities.

10. Health services

- MoH and MLSW to monitor all health care institutions and ensure that infrastructure and assistive staff are appropriate and helpful to people with disabilities.

- While every form of categorization of persons with disabilities as well as social care and care in providing their care should be carefully developed according to the character of the existing changes in the developmental scale of the disorders and in accordance with the concerns of these persons with disabilities , taking into account the degree of impairment and disability on one side and, on the other hand, their needs.

\section{For MEST and MED}

Creating equal opportunities for people with disabilities in the education system by increasing the degree of:

- Implementation of legislation in the field of education for persons with disabilities;

- Provide an inclusive education system in school institutions, professional development programs for inclusive education for teachers and people involved in the education system;

- Improving the competences on disability at the municipal level;

- Services should be provided by relevant institutions in the field of education, social affairs and other civil service. From the facts presented by the respondents' data in the report, it is evident that there is a lack of knowledge of sign language in Kosova and the lack of recognition of bilingualism;

- Creation of spaces that allow access to and respect of sign language, health institutions, educational institutions, legal institutions, police and other important sectors.

\section{Governmental organizations}

Social protection:

- Improving social services, reflecting the fundamental rights and freedoms of people with disabilities, increasing the economic living standards of persons with disabilities and families by creating and implementing a coherent 
legal framework for the access of people with disabilities limited to a greater spectrum of community service quality.

\section{Budget Assistance for Assistance:}

- For a more inclusive living, people with disabilities need help and maintenance. Government institutions provide these free means and this law to meet this need for people with disabilities.

\section{Employment:}

To offer people with disabilities equal opportunities in employment and in some cases where appropriate qualification has priority.

\section{Bibliography}

[1] Law on Pensions of Persons with Disabilities in Kosova;

[2] The Law on Material Support for Families of Children with Permanent Disabilities;

[3] Convention on the Protection of the Rights of the Child;

[4] Different research;

[5] Documents from NGO Handikos;

[6] National Report on Persons with Disabilities

[7] A comprehensive policy framework on the issue of disability in Kosova, drafted by HandiKos and UNMIK;

[8] Albania's National Strategy on People with Disabilities;

[9] The Ombudsperson's Annual Report 2017;

[10] UNICEF Study, Justice Denied: The State of Education of Children with Special Needs in Post-Conflict Kosova;

[11] Statistical Office, Publication of Social Welfare Statistics for Q2 2017;

[12] Broad Survey of Persons with Disabilities in Kosova;

[13] World Report on Disability, the Association of Deaf Offsprings of Kosova;

[14] Council for the Advancement of the Rights of Persons with Disabilities in Kosova. 